\title{
Panorama epigenético del mesotelioma pleural maligno
}

\section{Epigenetic panorama of malignant pleural mesothelioma}

\author{
Aldo Manuel Álvarez-Morán,* Pablo Ávila-Sánchez ${ }^{\ddagger}$ \\ *Hospital Ángeles Puebla; ${ }^{\ddagger}$ Universidad Anáhuac de Puebla, Puebla, México.
}

\begin{abstract}
RESUMEN. El mesotelioma pleural maligno es un tumor con una incidencia relativamente baja, en donde gran parte de su carcinogénesis involucra factores epigenéticos que mantienen su heterogeneidad; $y$ en ocasiones, son un blanco terapéutico, o bien un obstáculo a la efectividad en los tratamientos actuales. Esta revisión resume los principales mecanismos de desregulación epigenética involucrados en la patogenia del mesotelioma pleural maligno, tales como la hipermetilación mediada por ADNmetiltransferasas de distintos genes supresores de tumores, así como su relación con la exposición a fibras de asbesto que es el principal factor de riesgo. Su génesis se relaciona a inflamación crónica por radicales libres que culmina en alteraciones cromosómicas, inestabilidad genómica y expresión de genes que promueven la invasión tumoral y angiogénesis. Existen otras vías independientes de metilación que producen silenciamiento génico como el complejo Polycomb y la mutación de la vía SWI/ SNF. Por último, se mencionan otros mecanismos epigenéticos como la hipometilación con pérdida de impronta y activación de genes CG que inducen respuestas inmunológicas, así como la acetilación, desacetilación y desmetilación en el contexto de la cromatina e histonas. Todo lo previo con el objetivo de saber el uso clínico en cuanto al diagnóstico y tratamiento actual epigenético.
\end{abstract}

Palabras clave: Mesotelioma pleural maligno, asbesto, epigenética, hipermetilación, inestabilidad genómica.

\section{INTRODUCCIÓN}

El mesotelioma pleural maligno (MPM) humano es un tumor invariablemente mortal debido a su heterogeneidad. Muchos factores se encuentran implicados en su formación, como la exposición a fibras de asbesto y el virus 40 del simio. La incidencia anual del MPM es relativamente baja, estimándose en un rango de 0.6 a 30/1'000,000, pero la ocurrencia global se espera aumente continuamente conforme vayan incrementando más décadas., ${ }^{1,2}$ El MPM es extremadamente heterogéneo en su morfología y fenotipos moleculares. El período de latencia para el desarrollo de

Correspondencia:

Dr. Aldo Manuel Álvarez-Morán

Hospital Ángeles Puebla.

Correo electrónico: mdald73@hotmail.com

Trabajo recibido: 21-III-2019; aceptado: 16-VIII-2019
ABSTRACT. Malignant pleural mesothelioma is a tumor with a relative low incidence, where a large part of his carcinogenesis involves epigenetics factors that keeps his heterogeneity and in sometimes are a therapeutic target or an obstacle to the effectiveness in the newest treatments. This review summarizes the principal epigenetic dysregulation mechanisms involved in the MPM pathogeny such as hypermethylation mediated by DNA methyltransferases (DNMT) in different tumor suppressor genes, and the relation with asbestos fibers exposure that is the main risk factor. His genesis is related with chronic inflammation mediated by free radicals that produces chromosomal alterations, genomic instability and more expression of angiogenesis and tumor invasion factors like EGFR, FGFR, TGF-B and PDGF. We also describe the independent methylation pathways that produce gene silencing such as Polycomb complex and $\mathrm{SWI}$ SNF mutation. Finally, we mention others epigenetic mechanisms such as hypomethylation with imprint loss and CG gene activation that induce immunological responses, as well as acetylation, deacetylation and demethylation mechanism in the chromatin and histone context. All previous with the objective to know the clinical use of epigenetic diagnosis and treatment.

Keywords: Malignant pleural mesothelioma, abesto, epigenetics, hypermethylation, genomic instability.

MPM va 10 a 50 años después de la exposición al asbesto. El pronóstico de MPM es casi siempre pobre, con una media de supervivencia de 12 meses desde su diagnóstico. ${ }^{2,3}$

La heterogeneidad intratumoral se refiere a una mezcla de diferencias fenotípicas, funcionales y genéticas dentro de las células cancerígenas con varios estatus jerárquicos o de diferenciación dentro de un tumor. Esta heterogeneidad ha sido considerada como el mayor obstáculo en la efectividad de las terapias contra el cáncer, manifestándose en su sensibilidad a las diferentes terapias. Existe poca información acerca de las modificaciones epigenéticas que hablen de esta heterogeneidad. ${ }^{3,4}$

Las modificaciones epigenéticas son alteraciones heredables y estables de los genes que no cambian la secuencia del ADN; entre ellas tenemos metilación del ADN, modificación de las histonas y modificaciones e interferencia de ARN no codificante. Por un lado, la hipermetilación en el promotor de los genes relacionados con el cáncer inducen el silenciamiento o disminución de la regulación 
Neumol Cir Torax. 2019; 78 (4): 395-403

de genes supresores tumorales o genes reparadores. En cambio, la hipometilación del ADN conduce a la activación de oncogenes y la inestabilidad genómica. La aberración en la metilación del ADN juega un papel importante en la generación de la heterogeneidad de las células tumorales, lo cual abre la posibilidad de que el MPM manifieste estas aberraciones epigenéticas. ${ }^{4-6}$

Se desconoce con exactitud cuáles son los mecanismos por lo que las fibras de asbesto promueven el desarrollo de este tipo de cáncer; sin embargo, la teoría más aceptada es la inducción de inflamación y vías de señalización en la transformación de oxígeno reactivo generada por las fibras de asbesto. En este artículo se aborda un panorama del perfil epigenético del MPM y los mecanismos que propician estas modificaciones epigenéticas. ${ }^{6-8}$

\section{Alteraciones moleculares inducidas por el asbesto}

La carcinogénesis en el MPM está relacionada al asbesto, ocasionando una inflamación crónica que promueve la liberación de radicales libres de oxígeno que alteran los componentes intracelulares y así promover la mutación del ADN y la transformación de éste., ${ }^{9}, 10$ Las fibras de asbesto también contienen iones de hierro y pueden inducir hemolisis al secuestrar hierro desde la hemoglobina; esto es particularmente importante, pues el hierro libre libera $\mathrm{H}_{2} \mathrm{O}_{2}$ de forma desproporcionada, y éste a su vez libera radicales hidroxilos $(\mathrm{OH})$ que oxidan el $\mathrm{ADN}$, liberándose ácidos nucleicos, proteínas y lípidos. ${ }^{10,11}$ El ADN dañado, si no es reparado de forma adecuada, es altamente mutagénico y puede provocar inestabilidad genómica y epigenética. ${ }^{11}$
Existen otros mecanismos involucrados de cómo las fibras de asbesto causan MPM (Figura 1). Hay cuatro modelos propuestos relacionados a las fibras de asbesto que inducen daños genéticos y celulares, son los siguientes:

1. Especies reactivas de oxígeno generadas por las fibras de amianto, que con su superficie expuesta conduce a daños en el ADN y rotura de la membrana de las células. Macrófagos que fagocitan las fibras de asbesto, pero no pueden digerirlas y producen abundantes especies reactivas de oxígeno. ${ }^{12}$

2. Las fibras amianto también son engullidas por las células mesoteliales, interfiriendo físicamente con el proceso mitótico de la célula, ciclo que es cortado por la interrupción de los husos mitóticos. Otro aspecto importante es el enredo de fibras de amianto con los cromosomas o los husos mitóticos, lo que puede dar lugar a cromosomas estructuralmente dañados y generar aneuploidías de las células mesoteliales normales.12,13

3. Las fibras de amianto pueden absorber una variedad de proteínas y productos químicos que pueden resultar en la acumulación de moléculas peligrosas incluyendo carcinógenos.

4. Las células mesoteliales y macrófagos expuestos al asbesto liberan una variedad de citocinas y factores de crecimiento que inducen inflamación y promoción de tumores. ${ }^{14}$ Los que incluyen factor de necrosis tumoral $\alpha$, interleucina $1 \beta$, factor de crecimiento transformante $\beta$ y factor de crecimiento derivado de plaquetas. Se ha demostrado que el factor de necrosis tumoral- $\alpha$ puede activar el factor nuclear- $\kappa \mathrm{B}$, que conduce a la supervivencia de

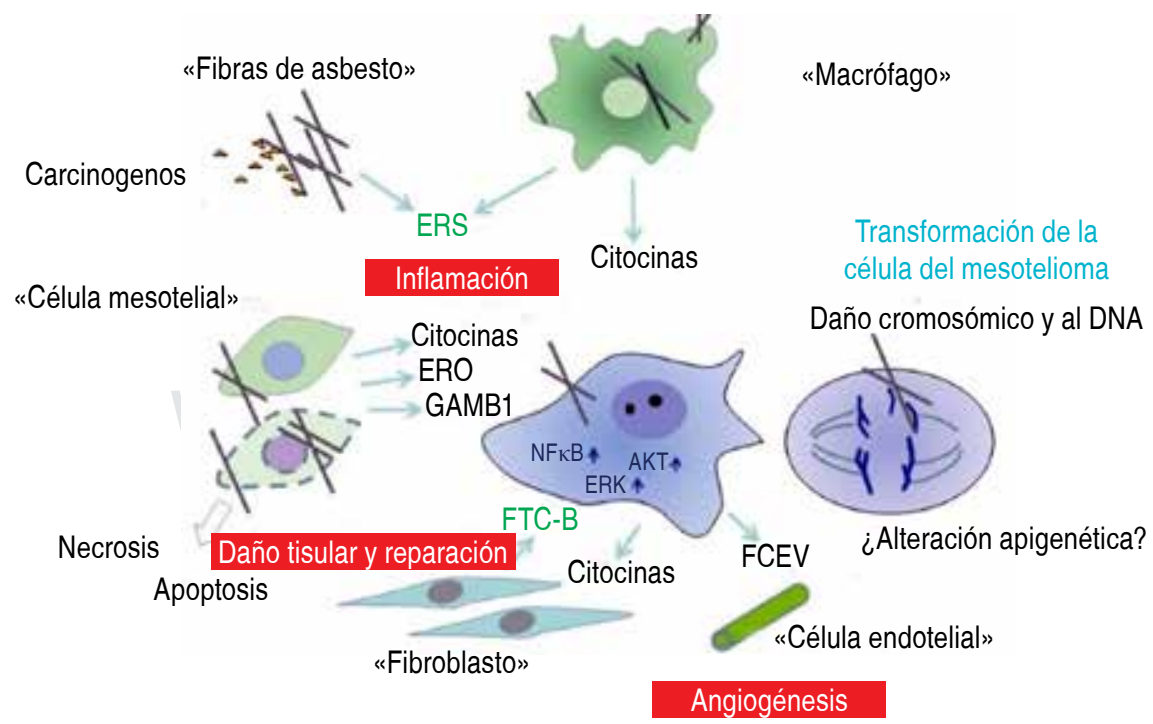

Figura 1: Posibles mecanismos de carcinogénesis inducida por asbesto. Abreviaturas: GAMB1 = proteína de alta movilidad del grupo Box 1. ERO = especies reactivas del oxígeno. FTC $-\beta=$ factor de crecimiento transformante $\beta$. FCEV = factor de crecimiento endotelial vascular. 
las células mesoteliales e inhibe la citotoxicidad inducida por el asbesto. ${ }^{15}$ La proteína del grupo de alta movilidad box 1 (GAMB1) se libera de las células mesoteliales que están expuestas al asbesto y luego sufren muerte celular necrótica, promoviendo una respuesta inflamatoria.

Así, la señalización activada entre células mesoteliales, células inflamatorias, fibroblastos y otras células estromales crea un conjunto de células mesoteliales que albergan aneuploidía y daño en el ADN, desarrollando células cancerosas y culminar en un microambiente tumoral que las soporta y las nutre. 16,17

\section{La metilación del ADN}

La desregulación epigenética permite cambios en la expresión de los genes, fenómenos que se han presentado en gran medida en el MPM. Alteraciones en la metilación del ADN juegan un papel importante en la adquisición del potencial maligno del MPM..$^{18,19}$ Las islas CpG metiladas han mostrado afectar el proceso oncogénico en el MPM, incluyendo proliferación celular incontrolada, diferenciación, alteración en la apoptosis y su alta capacidad de invasión. Por ejemplo, las fibras de asbesto aumentan la prevalencia de metilación de promotores aberrantes en el ciclo celular controlando los genes APC y RASSF1. La supervivencia en MPM ha sido atribuida a la metilación del promotor y el silenciamiento de genes como SFRP4, SFRP5, FHIT y SLCA20. ${ }^{20-22}$

En un estudio se encontraron 122 genes diferentemente regulados; de éstos, 118 estaban subregulados y cuatro suprarregulados con hipometilación, indicando con ello que poblaciones celulares en MPM pueden estar reguladas epigenéticamente y le confiere heterogeneidad intratumoral, propiciando propiedades más agresivas al mesotelioma. ${ }^{23}$

Múltiples ADN metiltransferasas e histona deacetilasas (HDACs) controlan genes supresores tumorales a través de la compactación de la cromatina y silenciamiento genético. Por ello, la inhibición de estas moléculas puede permitir la alteración de la expresión genética y provocar cambios en la proliferación celular, diferenciación y apoptosis. La inhibición HDACs conduce a la muerte celular por medio de la activación de la caspasa y la producción de radicales superóxido; además, produce hiperacetilación de proteínas no histónicas inhibiendo la angiogénesis, invasión y motilidad de las células tumorales. ${ }^{24-26}$

En el MPM sus células expresan altos niveles del factor del receptor de crecimiento epidérmico (EGFR, por sus siglas en inglés), y factor de crecimiento derivado de plaquetas (PDGF, por sus siglas en inglés). Otras moléculas implicadas en el MPM son el factor del receptor de crecimiento de fibroblastos (FGFR-1y3), factor de crecimiento transformante beta (TCF- $\beta$ ), factor de crecimiento parecido a la insulina (IGF-1R, por sus siglas en inglés) y factor de necrosis tumoral alfa de fusión a proteínas (NGR-hTNF- $\alpha$, por sus siglas en inglés), todos ellos implicados en la invasión y angiogénesis tumoral y en quienes se han expresado alteraciones epigenéticas. ${ }^{27-29}$

\section{Factores asociados a metilación}

La metilación del ADN de los loci génicos en MPM se ha relacionado con la edad, origen étnico, subtipo histológico y exposición al asbesto, lo que podría explicar las discrepancias entre las frecuencias de la metilación del ADN. El estado de metilación del locus IGFBP2 (proteína de unión al factor de crecimiento de la insulina) y locus GDF10 (proteína morfogenética ósea) es bastante mayor en MPM para pacientes japoneses que pacientes estadounidenses. ${ }^{30,31}$ El gen supresor RASSF1 es mayor de forma significativa en MPM epitelioide que en sarcomatoide..$^{32,33}$ Los mesoteliomas epitelioides y sarcomatoides presentan metilación diferencial en 87 islas CpG. Una asociación significativa entre la exposición al asbesto y metilación del ADN en los loci de los genes MT1A y MT2A, también se ha descrito en MPM. La metilación de islas CpG en los genes CCND2, CDKN2A, CDKN2B, HPPBP1 y RASSF1 ha demostrado que la metilación del ADN en el locus RASSF1 se correlaciona con un mayor número de cuerpos de asbesto en el pulmón. ${ }^{34-36}$

\section{Metilación y diagnóstico a través de ADN}

La metilación del ADN podría ser útil para el diagnóstico de MPM. Recién se sugirió que la metilación del ADN en tres loci específicos, TMEM30B, KAZALD1 y MAPK13, podrían ser útiles en el diagnóstico diferencial de MPM. Otros estudios han mostrado alteraciones de metilación en genes individuales, tales como aquellos que codifican un represor transcripcional (HIC1), un proapoptótico proteína (PYCARD), un supresor de tumores (LZTS1) y un transportador (SLC6A20), y se han asociado con un buen o mal pronóstico. ${ }^{37,38}$

\section{Regulación epigenética en la expresión génica del mesotelioma}

La metilación del ADN es el principal mecanismo epigenético que media los cambios dinámicos en la expresión génica durante la homeostasis celular normal y la diferenciación tisular, así como genes restringidos de células germinales, ADN repetitivo. ${ }^{39,40}$ Se han identificado tres metiltransferasas de ADN principales (DNMT1, 3A y 3B) en células somáticas normales, todas median la transferencia de un grupo metilo de S-adenosil-metionina a la posición 5 de la citosina en el contexto de CpG. ${ }^{40,41}$ Los grupos de dinucleótidos CpG están localizados en 
Tabla 1: Genes frecuentemente hipermetilados en MPM.

\begin{tabular}{|l|l|}
\hline APC1A & P151NK4B \\
\hline APC1B & P16 \\
BMP3b & RARB \\
\hline CDH1 & RASSF1A \\
\hline DAPK & SFRPs \\
\hline ESR1 & SLC6A20 \\
FHIT & SYK \\
\hline IGFBP3 & TMEM30B \\
\hline KAZALD1 & THBD \\
\hline MAPK13 & TMEM30B \\
\hline MGMT & TYMP \\
P14ARF & WIF-1 \\
\hline
\end{tabular}

MPM = mesotelioma pleural maligno

promotores de aproximadamente el $60 \%$ de los genes; la mayoría de estas islas no están metiladas, lo que permite una estructura relajada y transcripcional activa (eucromatina). ${ }^{42-45}$

Durante la transformación maligna, la sobreexpresión o la orientación aberrante de los componentes de la maquinaria de metilación del ADN produce un silenciamiento epigenético de los genes relacionados con la diferenciación, muchos son supresores de tumores. ${ }^{46,47}$

La desmetilación del ADN es pasiva durante la replicación del ADN. Durante la transformación maligna, la cantidad total de CpG metiladas se reduce notablemente (hasta un 50\%). Mientras que la desmetilación del ADN en todo el genoma puede atribuirse a una reparación deficiente del ADN. ${ }^{47-49}$

La acetilación, desacetilación, metilación y desmetilación han sido las modificaciones de histonas más ampliamente caracterizadas en células normales y células malignas. La acetilación de histonas está mediada por una variedad de histonas acetiltransferasas (HAT), mientras que la desacetilación de histonas está mediada por HDAC. ${ }^{50,51}$ La acetilación de histonas aumenta la carga negativa neta que conduce a la repulsión del ADN, la relajación de la cromatina y la activación de la expresión génica. ${ }^{52,53}$

\section{Silenciamiento de genes supresores mediado por metilación}

En un estudio se asoció la extensión de la metilación de algunos genes con la carga de asbesto pulmonar y la supervivencia general. Otro estudio demostró que 387 genes (6.3\%) que estaban hipermetilados en mesoteliomas en comparación con 544 genes (8.8\%) en adenocarcinomas de pulmón. Los niveles más altos de metilación del ADN se correlacionaron con una disminución de la supervivencia del paciente. Tres genes (TMEM30B, KAZALD1 y MAPK13) fueron específicamente hipermetilados en MPM. ${ }^{54-57}$ Otros genes con alteraciones en la metilación se muestran en la Tabla 1. Además, se ha demostrado que los genes DNMT1, DNMT3A y DNMT3B se encuentran sobreexpresados en la mayoría de las líneas de MPM y se correlacionan con una supervivencia más corta. ${ }^{58-60}$

\section{Pérdida de impronta (PI) y desrepresión de genes CG}

La hipometilación del ADN se ha implicado con la pérdida de impronta (PI), la represión de secuencias retrovirales endógenas y la activación de genes CG que pueden aumentar la proliferación, la inestabilidad genómica y la resistencia a la apoptosis durante la transformación maligna. ${ }^{61-63} \mathrm{~A}$ la fecha se han registrado más de 270 genes GC, el $75 \%$ de ellos se expresan sólo en los testículos normales y en las neoplasias malignas. ${ }^{63,64}$

En general, la magnitud de la represión del gen CG en el cáncer coincide con la etapa avanzada de la enfermedad y la activación de estos genes mejora el fenotipo maligno de las células cancerosas. ${ }^{65,66}$ Por ejemplo, BORIS/CTCFL regula al alza h-TERT e inhibe la apoptosis en células cancerosas. MAGE-A11 inhibe la función del supresor de tumores RBL1/ p107 y MAGE-B2 aumenta la actividad E2F para promover la progresión del ciclo celular. MAGE-A2 y MAGE-C2 alteran la función de p53 al inhibir directamente la unión de p53 a los promotores diana, promoviendo la desacetilación (inactivación) de p53.67-69

\section{Silenciamiento epigenético mediado por complejo Polycom}

Las proteínas del grupo Polycomb (PcG) son determinantes críticos de la pluripotencia y diferenciación de las células madre, así como la expresión de genes aberrantes durante la transformación maligna. ${ }^{69,70}$ Se han identificado dos complejos principales de represores Polycomb (PRC) en mamíferos..$^{70-72} \mathrm{El}$ complejo de iniciación, PRC-2, contiene subunidades EZH1/EZH2, SUZ12, EED y RBAP46/48, y media la trimetilación de la histona 3 lisina (H3K27Me3). El complejo de mantenimiento, PRC-1, que contiene subunidades PCAF, PHC, RING1, CBX y BMI1, media la ubiquitinación de H2AK119 (H2AK119Ub). ${ }^{73-75}$ Se ha demostrado la sobreexpresión de EZH2 en alrededor del $80 \%$ de los MPM primarios (la mayoría de los cuales eran epitelioides). ${ }^{75,76}$ En conjunto, estos experimentos fueron la primera demostración de que EZH2 se sobreexpresa en MPM y que el PRC-2 es un objetivo terapéutico potencial en estas neoplasias. ${ }^{77,78} \mathrm{El}$ análisis posterior de TCGA ha confirmado la regulación positiva de EZH2 en MPM, así 
como la asociación significativa entre la sobreexpresión de EZH2 y la supervivencia reducida de pacientes con MPM (Figura 2A). Un análisis adicional demuestra que la sobreexpresión de SUZ12 también augura una supervivencia pobre en pacientes con MPM (Figura 2B). En contraste, no parece haber ninguna asociación entre la expresión de EED y la supervivencia de los pacientes con MPM (Figura 2C).

\section{SWI/SNF}

SWI/SNF son complejos-homólogos de mamíferos de la levadura trithorax, funcionan para antagonizar las actividades represivas de PRC-2 en parte, al interrumpir los contactos ADN-nucleosoma y facilitar el movimiento, expulsión o sustitución de los nucleosomas para mejorar la accesibilidad del factor de transcripción al ADN. ${ }^{79-81}$ Los genes que codifican complejos SWI/SNF se encuentran entre los genes mutados con más frecuencia en los cánceres humanos. ${ }^{82,83}$ Se ha descrito un enriquecimiento significativo para las mutaciones en los genes involucrados en las vías SWI/SNF, incluidas las mutaciones homocigotas de SMARCA4, ARID2 y PBRM1. En un estudio se analizaron las mutaciones que involucraron genes que codifican componentes SWI/SNF, pero sólo observaron mutaciones SETD2 en el 8\% de las muestras, así como mutaciones que involucran dos metiltransferasas de histonas adicionales (SETDB1 y SETD5) en aproximadamente el $3 \%$ de las muestras. ${ }^{84-86}$

\section{La epigenética en el tratamiento del mesotelioma}

El MPM exhibe el silenciamiento de los genes supresores de tumores a través de la hipermetilación de ADN específica del sitio y/o de los complejos represores de Polycomb en el contexto de la hipometilación del genoma que facilita la represión de los genes CG . $^{87-89}$ Esta «paradoja de la metilación del $A D N »$, recapitula los estados epigenómicos en las células germinales normales y proporciona el fundamento para el desarrollo de regímenes epigenéticos que inducen la detención del crecimiento/ apoptosis a través de la restauración de la expresión del gen supresor de tumores, al mismo tiempo que aumenta la inmunidad antitumoral mediante la modulación del microentorno tumoral. ${ }^{90-92}$

Dados sus roles directos en el silenciamiento de los genes supresores de tumores y el mantenimiento de la pluripotencia, los DNMT son objetivos atractivos para la terapia de MPM..$^{93,94}$ La falta de eficacia de los agentes de hipometilación de ADN en tumores sólidos, hasta la fecha puede estar relacionada con el hecho de que estos agentes se han administrado a niveles máximos que resultan en mielosupresión en lugar de administrarse crónicamente a dosis más bajas para lograr efectos farmacodinámicos sin toxicidad sistémica. ${ }^{95-97}$ Estos compuestos se inactivan rápido por la citidina desaminasa (CDA), que se encuentra presente en casi todos los órganos, en especial en el tracto gastrointestinal. ${ }^{98,99}$ La hipometilación del ADN sistémico mediada por DAC-THU da lugar a aumentos significativos en la hemoglobina fetal sin neutropenia, trombocitopenia o linfopenia. ${ }^{100,101}$ Las estrategias de combinación como el uso de inhibidores de HDAC para sensibilizar las células a la apoptosis mediada por TRAIL, o el uso de flavopiridol para mejorar la detención del crecimiento mediada por romidepsina y la apoptosis pueden ser apropiadas para evaluar en futuros ensayos clínicos. ${ }^{101-103}$ Puede ser posible explotar, aún más, las mutaciones BAP1 para la terapia MPM. BAP1 funciona para estabilizar el BRCA-1 y promover el reclutamiento dependiente de poli (ADP-Ribosa) del complejo de poliquial deubiquitinasa PR-DUB a los sitios de daño del ADN. ${ }^{104-106}$ Esta actividad depende de la actividad de la deubiquitinasa y de la fosforilación de BAP1. ${ }^{107}$ Las mutaciones BAP1, que siempre parecen manifestarse como pérdida de función, disminuyen los niveles de BRCA-1 e inhiben la reparación del ADN de doble cadena. En un en-
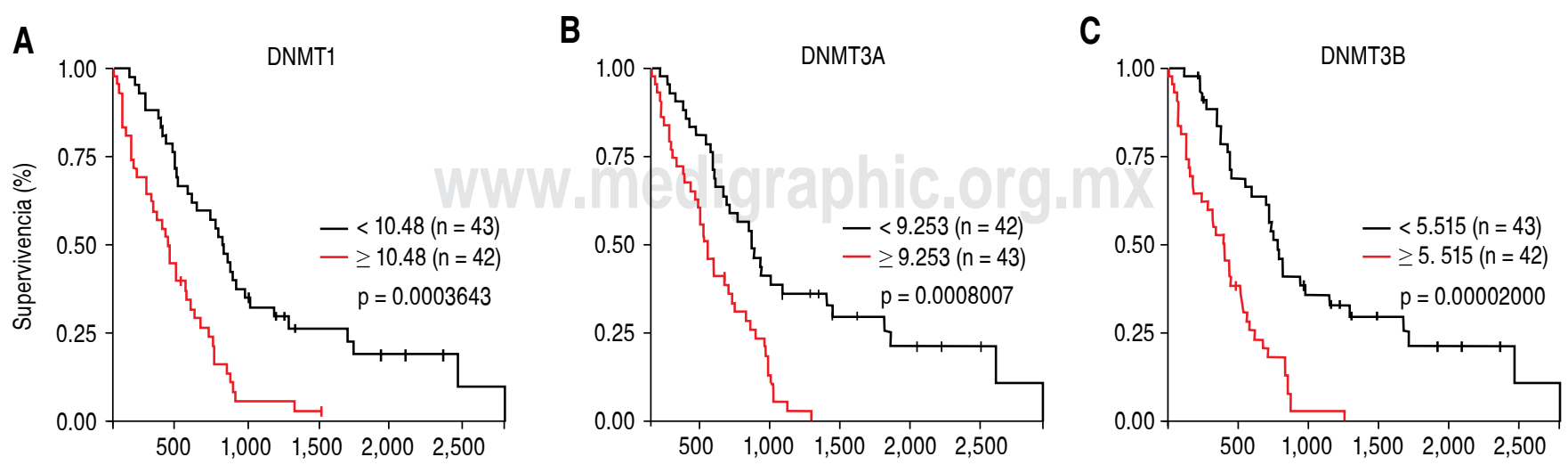

Figura 2: Asociación de los niveles de expresión DNMT intratumoral con la supervivencia de pacientes con MPM. Las curvas de Kaplan Meier demuestran que la magnitud de la expresión de DNMT1, DNMT3A y DNMT3B detectada por las técnicas de RNA-seq (A, B, y C, respectivamente) tienen un impacto adverso en la supervivencia del paciente. 
sayo se observó que una isoforma BAP1 que contiene parte del dominio catalítico sensibilizó células MPM al inhibidor de PARP1, olaparib. Esta sensibilidad puede aumentarse mediante un tratamiento concomitante con el inhibidor dual de PI3K-mTOR, GDC0980, que se regula a la baja el BRCA-1. Estas estrategias podrían mejorar las respuestas a cisplatino/pemetrexed en pacientes con MPM. ${ }^{106}$

Estos hallazgos, junto con las observaciones recientes del microambiente, tienen un impacto en el resultado de los pacientes con MPM para una combinación convincente de inmunoterapias epigenéticas para estas neoplasias. ${ }^{106-107}$

\section{CONCLUSIONES}

El MPM es una enfermedad con incidencia baja, pero con un comportamiento agresivo, cuya supervivencia no va más allá de 12 meses una vez hecho el diagnóstico. Su origen se ha relacionado a la exposición crónica del asbesto como factor principal, siendo este componente esencial en los cambios estructurales a nivel molecular; y de cuyos estudios hay mucha evidencia acerca de su comportamiento genético y en menor medida epigenético, lo que le confiere un comportamiento bastante heterogéneo. Las modificaciones epigenéticas en el MPM permiten un conocimiento más amplio sobre la carcinogénesis de este tumor y un acercamiento a nuevas herramientas diagnósticas. Las desregulaciones epigenéticas requieren un mantenimiento activo y son potencialmente reversibles, por lo que las hace un blanco terapéutico.

El estudio del metiloma ha permitido realizar diagnósticos diferenciales gracias a la metilación de algunos loci en específicos, como TMEM30B, KAZAZD1, MAPK13 y demostrar mayores supervivencias a pacientes que presenten baja frecuencias de metilaciones.

Es importante mencionar la exposición a las fibras de asbesto como principal factor de riesgo asociado a la metilación de los genes supresores de tumor vistos en las células mesoteliales pleurales tales como APC y RASSF1, además de sus efectos directos celulares como inflamación crónica mediada por radicales libres, oxidación del ADN y hemólisis con liberación de iones hidroxilo, ruptura intracatenaria más fragmentación cromosómica subsecuente y liberación de citocinas proinflamatorias con mayor expresión de factores de crecimiento angiogénico o de invasión tumoral. Otro aspecto que sirve como objetivo terapéutico.

Las respuestas genómicas relacionadas a la metilación concluyen en un silenciamiento génico, siendo comprobado en genes supresores de tumor como SFRP4, FHIT, SLCA20. Otro aproximamiento diagnóstico que se puede observar por la metilación es la sobreexpresión de DNMT en pacientes con MPM y, consecuente a esto, ser un objetivo terapéutico atractivo; sin embargo, los esfuerzos clínicos por su inhibición han sido decepcionantes. Estudios futuros deberían enfocarse en la búsqueda de la aproximación terapéutica a la inhibición de las DNMT, dado que ya se ha comprobado una mejoría en la supervivencia.

Se ha visto una mayor asociación de metilación en edades avanzadas y etnias como los japoneses. No obstante, la mayor asociación a cambios histológicos en proliferación, diferenciación, invasión y reducción de apoptosis se ha visto con la mayor metilación de las islas $\mathrm{CpG}$ en genes como CCND2, CDKN2A y asociado a cuerpos de asbesto con RASSF1.

A pesar de que la metilación es el mecanismo epigenético más estudiado, existen otras modificaciones que conducen al silenciamiento de los genes supresores de tumores, como la activación del complejo Polycomb y la mutación de la vía SWI/SNF. La desacetilación mediada por HDAC se ha visto en el gen p53 y otros aspectos como la acetilación mediada por HAT o desmetilación por KDMs.

Las modificaciones en las histonas hablan de una estabilidad en la cromatina y tienen una gran relación con las HDCA, por lo que las hacen potencialmente un blanco terapéutico. Al presente, existen estudios con inhibidores como vorinostat, empero, no hay grandes resultados debido a la poca expresión en el MPM.

Es claro que falta mucho por saber en cuanto a las modificaciones y/o cambios epigenéticos en el MPM. La infinidad de información que se tiene nos abre otro panorama para ajustar estrategias terapéuticas personalizadas encaminadas a revertir dichas alteraciones y, con ello, poder identificar de manera temprana y oportuna a aquellos pacientes que sean susceptibles a dichos tratamientos si se hace una búsqueda de marcadores epigenéticos que en algún momento de su enfermedad se encuentren sobreexpresados o silenciados.

\section{REFERENCIAS}

1. Kim MC, Kim NY, Seo YR, Kim Y. An integrated analysis of the genome-wide profiles of DNA methylation and mRNA expression defining the side population of a human malignant mesothelioma cell line. J Cancer 2016;7(12):1668-1679. doi: 10.7150/jca.15423.

2. Sage AP, Martinez VD, Minatel BC, et al. Genomics and epigenetics of malignant mesothelioma. High Throughput 2018;7(3). pii: E20. doi: $10.3390 / \mathrm{ht} 7030020$.

3. Feinberg AP, Ohlsson R, Henikoff S. The epigenetic progenitor origin of human cancer. Nat Rev Genet 2006;7(1):21-33. doi: 10.1038/nrg1748.

4. Magee JA, Piskounova E, Morrison SJ. Cancer stem cells: impact, heterogeneity, and uncertainty. Cancer Cell 2012;21(3):283-296. doi: 10.1016/j.ccr.2012.03.003.

5. Pietras A. Cancer stem cells in tumor heterogeneity. Adv Cancer Res 2011; 112:255-281. doi: 10.1016/B978-0-12-387688-1.00009-0.

6. Laird PW. Principles and challenges of genomewide DNA methylation analysis. Nat Rev Genet 2010;11(3):191-203. doi:10.1038/nrg2732.

7. Jacinto FV, Ballestar E, Esteller M. Methyl-DNA immunoprecipitation (MeDIP): hunting down the DNA methylome. Biotechniques 2008;44(1):35. doi: 10.2144/000112708. 
8. Blayney JK, Ceresoli GL, Castagneto B, et al. Response to chemotherapy is predictive in relation to longer overall survival in an individual patient combined-analysis with pleural mesothelioma. Eur J Cancer 2012;48(16):2983-2992. doi: 10.1016/j.ejca.2012.05.018.

9. Vandermeers F, Neelature Sriramareddy S, Costa C, Hubaux R, Cosse JP, Willems $\mathrm{L}$. The role of epigenetics in malignant pleural mesothelioma. Lung Cancer 2013;81(3):311-318. doi: 10.1016/j. lungcan.2013.05.014.

10. Shukla A, Shukla A. Current Therapies for Malignant Mesothelioma. J Cancer Sci Ther 2014;6: 306-309.

11. Lee AY, He B, You L, et al. Expression of the secreted frizzled-related protein gene family is downregulated in human mesothelioma. Oncogene 2004; 23(39):6672-6676. doi: 10.1038/sj.onc.1207881.

12. Kohno H, Amatya VJ, Takeshima Y, et al. Aberrant promoter methylation of WIF-1 and SFRP1, 2, 4 genes in mesothelioma. Oncol Rep 2010;24(2):423-431. doi: 10.3892/or_00000875.

13. Christensen BC, Houseman EA, Godleski JJ, et al. Epigenetic profiles distinguish pleural mesothelioma from normal pleura and predict lung asbestos burden and clinical outcome. Cancer Res 2009;69(1):227-234. doi: 10.1158/0008-5472.CAN-08-2586.

14. Guarrera S, Viberti C, Cugliari G, et al. Peripheral Blood DNA methylation as potential biomarker of malignant pleural mesothelioma in asbestos-exposed subjects. J Thorac Oncol 2019;14(3):527-539. doi: 10.1016/j.jtho.2018.10.163.

15. Tomii K, Tsukuda K, Toyooka S, et al. Aberrant promoter methylation of insulin-like growth factor binding protein-3 gene in human cancers. Int J Cancer 2007;120(3):566-573. doi: 10.1002/ijc.22341.

16. Kimura K, Toyooka S, Tsukuda K, et al. The aberrant promoter methylation of BMP3b and BMP6 in malignant pleural mesotheliomas. Oncol Rep 2008; 20(5):1265-1268.

17. Toyooka S, Pass HI, Shivapurkar N, et al. Aberrant methylation and simian virus 40 tag sequences in malignant mesothelioma. Cancer Res 2001;61(15): 5727-5730.

18. Shivapurkar N, Toyooka S, Toyooka KO, et al. Aberrant methylation of trail decoy receptor genes is frequent in multiple tumor types. Int J Cancer 2004; 109(5):786-792. doi: 10.1002/ijc.20041.

19. Tsou JA, Galler JS, Wali A, et al. DNA methylation profile of 28 potential marker loci in malignant mesothelioma. Lung Cancer 2007;58(2):220-230. doi: 10.1016/j.lungcan.2007.06.015.

20. Yin Y, Morgunova E, Jolma A, et al. Impact of cytosine methylation on DNA binding specificities of human transcription factors. Science 2017;356(6337). pii: eaaj2239. doi: 10.1126/science.aaj2239.

21. Tsou JA, Shen LY, Siegmund KD, et al. Distinct DNA methylation profiles in malignant mesothelioma, lung adenocarcinoma, and non-tumor lung. Lung Cancer 2005;47(2):193-204. doi: 10.1016/j. lungcan.2004.08.003.

22. Suzuki M, Toyooka S, Shivapurkar N, et al. Aberrant methylation profile of human malignant mesotheliomas and its relationship to SV40 infection. Oncogene 2005;24(7):1302-1308. doi: 10.1038/ sj.onc.1208263.

23. Paik PK, Krug LM. Histone deacetylase inhibitors in malignant pleural mesothelioma: preclinical rationale and clinical trials. J Thorac Oncol 2010; 5(2):275-279. doi: 10.1097/JTO.0b013e3181c5e366.

24. Sekido T. Molecular pathogenesis of malignant mesothelioma. Carcinogenesis 2013;34(7):1413-1419. doi: 10.1093/carcin/bgt166.

25. Heintz NH, Janssen-Heininger YM, Mossman BT. Asbestos, lung cancers, and mesotheliomas: from molecular approaches to targeting tumor survival pathways. Am J Respir Cell Mol Biol 2010;42(2):133139. doi: $10.1165 / \mathrm{rcmb} .2009-0206 \mathrm{TR}$.
26. Toyokuni S. Mechanisms of asbestos-induced carcinogenesis. Nagoya J Med Sci 2009;71(1-2):1-10.

27. Dawson MA, Kouzarides T. Cancer epigenetics: from mechanism to therapy. Cell 2012;150(1):12-27. doi: 10.1016/j.cell.2012.06.013.

28. Tessarz P, Kouzarides T. Histone core modifications regulating nucleosome structure and dynamics. Nat Rev Mol Cell Biol 2014;15(11):703-708. doi: 10.1038/nrm3890.

29. Jin B, Robertson KD. DNA methyltransferases, DNA damage repair, and cancer. Adv Exp Med Biol 2013;754:3-29. doi: 10.1007/978-14419-9967-2_1.

30. Baylin SB, Jones PA. Epigenetic determinants of cancer. Cold Spring Harb Perspect Biol 2016;8(9). pii: a019505. doi: 10.1101/cshperspect. a019505.

31. Casalone E, Allione A, Viberti C, et al. DNA methylation profiling of asbestos-treated MeT5A cell line reveals novel pathways implicated in asbestos responses. Arch Toxicol 2018;92(5):1785-1795. doi: 10.1007/ s00204-018-2179-y.

32. Christensen BC, Marsit CJ, Houseman EA, et al. Differentiation of lung adenocarcinoma, pleural mesothelioma, and nonmalignant pulmonary tissues using DNA methylation profiles. Cancer Res 2009;69(15):6315-6321. doi: 10.1158/0008-5472.CAN-09-1073.

33. Zhu H, Wang G, Qian J. Transcription factors as readers and effectors of DNA methylation. Nat Rev Genet 2016;17(9):551-565. doi: 10.1038/ nrg.2016.83.

34. Shimbo T, Wade PA. Proteins that read DNA methylation. Adv Exp Med Biol 2016;945:303-320. doi: 10.1007/978-3-319-43624-1_13.

35. Yoon JH, Smith LE, Feng Z, et al. Methylated CpG dinucleotides are the preferential targets for G-to-T transversion mutations induced by benzo[a]pyrene diol epoxide in mammalian cells: similarities with the p53 mutation spectrum in smoking-associated lung cancers. Cancer Res 2001;61(19):7110-7117.

36. Bochtler M, Kolano A, Xu GL. DNA demethylation pathways: Additional players and regulators. Bioessays 2017;39:1-13. doi: 10.1002/ bies.201600178.

37. Yin X, Xu Y. Structure and function of TET enzymes. Adv Exp Med Biol 2016;945:275-302. doi: 10.1007/978-3-319-43624-1_12.

38. Ha K, Lee GE, Palii SS, et al. Rapid and transient recruitment of DNMT1 to DNA double-strand breaks is mediated by its interaction with multiple components of the DNA damage response machinery. Hum Mol Genet 2011;20(1):126-140. doi: 10.1093/hmg/ddq451.

39. Cai Y, Tsai HC, Yen RC, et al. Critical threshold levels of DNA methyltransferase 1 are required to maintain DNA methylation across the genome in human cancer cells. Genome Res 2017;27(4):533-544. doi: 10.1101/gr.208108.116.

40. An J, Rao A, Ko M. TET family dioxygenases and DNA demethylation in stem cells and cancers. Exp Mol Med 2017;49(4):e323. doi: 10.1038/ emm.2017.5.

41. Zoghbi HY, Beaudet AL. Epigenetics and human disease. Cold Spring Harb Perspect Biol 2016;8(2):a019497. doi: 10.1101/cshperspect. a019497.

42. Schomacher $\mathrm{L}$, Niehrs C. DNA repair and erasure of 5-methylcytosine in vertebrates. Bioessays 2017;39(3). doi: 10.1002/bies.201600218.

43. Schuermann D, Weber AR, Schär P. Active DNA demethylation by DNA repair: Facts and uncertainties. DNA Repair (Amst) 2016;44:92102. doi: 10.1016/j.dnarep.2016.05.013.

44. Van Tongelen A, Loriot A, De Smet C. Oncogenic roles of DNA hypomethylation through the activation of cancer-germline genes. Cancer Lett 2017;396:130-137. doi: 10.1016/j.canlet.2017.03.029. 
45. Audia JE, Campbell RM. Histone modifications and cancer. Cold Spring Harb Perspect Biol 2016;8(4):a019521. doi: 10.1101/ cshperspect.a019521.

46. Zhao Y, Garcia BA. Comprehensive catalog of currently documented histone modifications. Cold Spring Harb Perspect Biol 2015;7(9):a025064. doi: 10.1101/cshperspect.a025064.

47. Wapenaar H, Dekker FJ. Histone acetyltransferases: challenges in targeting bi-substrate enzymes. Clin Epigenetics 2016;8:59.

48. Hyun K, Jeon J, Park K, Kim J. Writing, erasing and reading histone lysine methylations. Exp Mol Med 2017;49(4):e324. doi: 10.1038/ emm.2017.11.

49. Yi X, Jiang XJ, Li XY, Jiang DS. Histone methyltransferases: novel targets for tumor and developmental defects. Am J Transl Res 2015;7(11):2159-2175.

50. Bueno R, Stawiski EW, Goldstein LD, et al. Comprehensive genomic analysis of malignant pleural mesothelioma identifies recurrent mutations, gene fusions and splicing alterations. Nat Genet 2016;48(4):407-416. doi: 10.1038/ng.3520.

51. Liu F, Killian JK, Yang M, et al. Epigenomic alterations and gene expression profiles in respiratory epithelia exposed to cigarette smoke condensate. Oncogene 2010;29(25):3650-3664. doi: 10.1038/ onc.2010.129.

52. Kumar R, Li DQ, Muller S, Knapp S. Epigenomic regulation of oncogenesis by chromatin remodeling. Oncogene 2016;35(34):44234436. doi: 10.1038/onc.2015.513.

53. Längst G, Manelyte L. Chromatin remodelers: From function to dysfunction. Genes (Basel) 2015;6(2):299-324. doi: 10.3390/ genes6020299.

54. Witkowski L, Foulkes WD. In Brief: Picturing the complex world of chromatin remodelling families. J Pathol 2015;237(4):403-406. doi: 10.1002/path.4585.

55. Rinn JL, Chang HY. Genome regulation by long noncoding RNAs. Annu Rev Biochem 2012;81:145-166. doi: 10.1146/annurevbiochem-051410-092902.

56. Rinn JL. IncRNAs: linking RNA to chromatin. Cold Spring Harb Perspect Biol 2014;6(8).pii: a018614. doi: 10.1101/cshperspect. a018614.

57. Meseure D, Drak Alsibai K, Nicolas A, Bieche I, Morillon A. Long noncoding RNAs as new architects in cancer epigenetics, prognostic biomarkers, and potential therapeutic targets. Biomed Res Int 2015;2015:320214. doi: 10.1155/2015/320214.

58. Davidovich C, Cech TR. The recruitment of chromatin modifiers by long noncoding RNAs: lessons from PRC2. RNA 2015;21(12):20072022. doi: 10.1261/rna.053918.115.

59. Bagwe AN, Kay PH, Spagnolo DV. Evidence that DNA methylation imbalance is not involved in the development of malignant mesothelioma. Anticancer Res 1997;17(5A):3341-3343.

60. Goto Y, Shinjo K, Kondo Y, et al. Epigenetic profiles distinguish malignant pleural mesothelioma from lung adenocarcinoma. Cancer Res 2009;69(23):9073-9082. doi: 10.1158/0008-5472.CAN-091595.

61. Foran E, Garrity-Park MM, Mureau C, et al. Upregulation of DNA methyltransferase-mediated gene silencing, anchorage-independent growth, and migration of colon cancer cells by interleukin-6. Mol Cancer Res 2010;8(4):471-481. doi: 10.1158/1541-7786.MCR-09-0496.

62. Hodge DR, Xiao W, Clausen PA, Heidecker G, Szyf M, Farrar WL. Interleukin-6 regulation of the human DNA methyltransferase (HDNMT) gene in human erythroleukemia cells. J Biol Chem 2001;276(43):39508-39511. doi: 10.1074/jbc.C100343200.
63. Yu M, Lou J, Xia H, et al. Global DNA hypomethylation has no impact on lung function or serum inflammatory and fibrosis cytokines in asbestos-exposed population. Int Arch Occup Environ Health 2017;90(3):265-274. doi: 10.1007/s00420-017-1195-1.

64. Gaudet F, Hodgson JG, Eden A, et al. Induction of tumors in mice by genomic hypomethylation. Science 2003;300(5618):489-492. doi: 10.1126/science.1083558 .

65. Salmaninejad A, Zamani MR, Pourvahedi M, Golchehre Z, Hosseini Bereshneh A, Rezaei N. Cancer/Testis antigens: expression, regulation, tumor invasion, and use in immunotherapy of cancers. Immunol Invest 2016;45(7):619-640. doi: 10.1080/08820139.2016.1197241.

66. De Smet C, Loriot A. DNA hypomethylation and activation of germlinespecific genes in cancer. Adv Exp Med Biol 2013;754:149-166. doi: 10.1007/978-1-4419-9967-2_7.

67. Simpson AJ, Caballero OL, Jungbluth A, Chen YT, Old LJ. Cancer/ testis antigens, gametogenesis and cancer. Nat Rev Cancer 2005;5(8):615-625. doi: 10.1038/nrc1669.

68. Zendman AJ, Ruiter DJ, Van Muijen GN. Cancer/testis-associated genes: identification, expression profile, and putative function. J Cell Physiol 2003; 194(3):272-288. doi: 10.1002/jcp.10215.

69. Renaud S, Loukinov D, Alberti L, et al. BORIS/CTCFL-mediated transcriptional regulation of the $h T E R T$ telomerase gene in testicular and ovarian tumor cells. Nucleic Acids Res 2011;39(3):862-873. doi: $10.1093 /$ nar/gkq827.

70. Dougherty CJ, Ichim TE, Liu L, et al. Selective apoptosis of breast cancer cells by siRNA targeting of BORIS. Biochem Biophys Res Commun 2008;370(1):109-112. doi: 10.1016/j.bbrc.2008.03.040.

71. Loriot A, Reister S, Parvizi GK, Lysy PA, Smet C. DNA methylationassociated repression of cancer-germline genes in human embryonic and adult stem cells. Stem Cells 2009;27(4):822-824. doi: 10.1002/ stem.8.

72. Schrump DS. Targeting epigenetic mediators of gene expression in thoracic malignancies. Biochim Biophys Acta 2012;1819(7):836-845. doi: 10.1016/j.bbagrm.2012.03.009.

73. Weiser TS, Guo ZS, Ohnmacht GA, et al. Sequential 5-Aza-2 deoxycytidine-depsipeptide FR901228 treatment induces apoptosis preferentially in cancer cells and facilitates their recognition by cytolytic T lymphocytes specific for NY-ESO-1. J Immunother 2001;24(2):151-161. doi: 10.1097/00002371-200103000-00010.

74. Sigalotti L, Coral S, Altomonte M, et al. Cancer testis antigens expression in mesothelioma: role of DNA methylation and bioimmunotherapeutic implications. Br J Cancer 2002;86(6):979-982. doi: 10.1038/sj.bjc.6600174.

75. Oliviero G, Brien GL, Waston A, et al. Dynamic protein interactions of the polycomb repressive complex 2 during differentiation of pluripotent cells. Mol Cell Proteomics 2016;15(11):3450-3460. doi: 10.1074/mcp. M116.062240.

76. Pasini D, Di Croce L. Emerging roles for Polycomb proteins in cancer. Curr Opin Genet Dev 2016;36:50-58. doi: 10.1016/j.gde.2016.03.01.

77. Poynter ST, Kadoch C. Polycomb and trithorax opposition in development and disease. Wiley Interdiscip Rev Dev Biol 2016;5(6):659-688. doi: 10.1002/wdev.244.

78. Pasini D, Cloos PA, Walfridsson J, et al. JARID2 regulates binding of the Polycomb repressive complex 2 to target genes in ES cells. Nature 2010;464(7286):306-310. doi: 10.1038/nature08788.

79. Katoh M. Functional proteomics of the epigenetic regulators ASXL1, ASXL2 and ASXL3: a convergence of proteomics and epigenetics for translational medicine. Expert Rev Proteomics 2015;12(3):317-328. doi: 10.1586/14789450.2015.1033409. 
80. Mantsoki A, Devailly G, Joshi A. CpG island erosion, polycomb occupancy and sequence motif enrichment at bivalent promoters in mammalian embryonic stem cells. Sci Rep 2015;5:16791. doi: 10.1038/ srep16791.

81. Harikumar A, Meshorer E. Chromatin remodeling and bivalent histone modifications in embryonic stem cells. EMBO Rep 2015;16:1609-19.

82. Kemp CD, Rao M, Xi S, et al. Polycomb repressor complex-2 is a novel target for mesothelioma therapy. Clin Cancer Res 2012;18(1):77-90. doi: 10.1158/1078-0432.CCR-11-0962.

83. LaFave LM, Beguelin W, Koche R, et al. Loss of BAP1 function leads to EZH2-dependent transformation. Nat Med 2015;21(11):1344-1349. doi: 10.1038/nm.3947.

84. Zauderer MG, Bott M, McMillan R, et al. Clinical characteristics of patients with malignant pleural mesothelioma harboring somatic BAP1 mutations. J Thorac Oncol 2013;8(11):1430-1433. doi: 10.1097/ JT0.0b013e31829e7ef9.

85. Kadoch C, Copeland RA, Keilhack H. PRC2 and SWI/SNF chromatin remodeling complexes in health and disease. Biochemistry 2016;55(11):1600-1614. doi: 10.1021/acs.biochem.5b01191.

86. Pulice JL, Kadoch C. Composition and function of mammalian SWI/SNF chromatin remodeling complexes in human disease. Cold Spring Harb Symp Quant Biol 2016;81:53-60. doi: 10.1101/ sqb.2016.81.031021.

87. Yoshikawa Y, Sato A, Tsujimura T, et al. Biallelic germline and somatic mutations in malignant mesothelioma: multiple mutations in transcription regulators including $\mathrm{mSWI} / S N F$ genes. Int J Cancer 2015;136(3):560-571. doi: 10.1002/ijc.29015.

88. Yoshikawa Y, Emi M, Hashimoto-Tamaoki T, et al. High-density array-CGH with targeted NGS unmask multiple noncontiguous minute deletions on chromosome 3p21 in mesothelioma. Proc Natl Acad Sci USA 2016; 113(47):13432-13437. doi: 10.1073/ pnas.1612074113.

89. Filipp FV. Crosstalk between epigenetics and metabolism-Yin and Yang of histone demethylases and methyltransferases in cancer. Brief Funct Genomics 2017;16(6):320-325. doi: 10.1093/bfgp/elx001.

90. Wolff F, Leisch M, Greil R, Risch A, Pleyer L. The double-edged sword of (re)expression of genes by hypomethylating agents: from viral mimicry to exploitation as priming agents for targeted immune checkpoint modulation. Cell Commun Signal 2017;15(1):13. doi: 10.1186/s12964-017-0168-z.

91. Kim K, Skora AD, Li Z, et al. Eradication of metastatic mouse cancers resistant to immune checkpoint blockade by suppression of myeloidderived cells. Proc Natl Acad Sci USA 2014;111(32):11774-11779. doi: 10.1073/pnas.1410626111.

92. Pathania R, Ramachandran S, Elangovan S, et al. DNMT1 365 is essential for mammary and cancer stem cell maintenance and tumorigenesis. Nat Commun 2015;6:6910. doi: 10.1038/ ncomms7910.

93. Yang J, Corsello TR, Ma Y. Stem cell gene SALL4 suppresses transcription through recruitment of DNA methyltransferases. J Biol Chem 2012;287(3): 1996-2005. doi: 10.1074/jbc.M111.308734.

94. Yogelzang NJ, Herndon JE 2nd, Cirrincione C, et al. Dihydro-5azacytidine in malignant mesothelioma. A phase II trial demonstrating activity accompanied by cardiac toxicity. Cancer and Leukemia
Group B. Cancer 1997;79(11):2237-2242. doi: 10.1002/(sici)10970142(19970601)79:11<2237::aid-cncr23>3.0.c0;2-w.

95. Schrump DS, Fischette MR, Nguyen DM, et al. Phase I study of decitabine-mediated gene expression in patients with cancers involving the lungs, esophagus, or pleura. Clin Cancer Res 2006;12(19):5777-5785. doi: 10.1158/1078-0432.CCR-06-0669.

96. Chabner BA, Johns DG, Coleman CN, Drake JC, Evans WH. Purification and properties of cytidine deaminase from normal and leukemic granulocytes. J Clin Invest 1974;53(3):922-931. doi: 10.1172/JCl107633.

97. Lavelle D, Vaitkus K, Ling Y, et al. Effects of tetrahydrouridine on pharmacokinetics and pharmacodynamics of oral decitabine. Blood 2012;119(5):1240-1247. doi: 10.1182/blood-2011-08-371690.

98. Wentworth DF, Wolfenden R. On the interaction of 3,4,5,6-tetrahydrouridine with human liver cytidine deaminase. Biochemistry 1975;14(23):5099-5105. doi: 10.1021/bi00694a012.

99. Newman EM, Morgan RJ, Kummar S, etal. A phase I, pharmacokinetic, and pharmacodynamic evaluation of the DNA methyltransferase inhibitor 5-fluoro-2'-deoxycytidine, administered with tetrahydrouridine. Cancer Chemother Pharmacol 2015;75(3):537-546. doi: 10.1007/ s00280-014-2674-7.

100. Tan K, Kanijo K, Momose S, et al. Mesothelin (MSLN) promoter is hypomethylated in malignant mesothelioma, but its expression is not associated with methylation status of the promoter. Hum Pathol 2010; 41(9):1330-1338. doi: 10.1016/j.humpath.2010.03.002.

101. Krug LM, Kindler HL, Calvert $\mathrm{H}$, et al. Vorinostat in patients with advanced malignant pleural mesothelioma who have progressed on previous chemotherapy (VANTAGE-014): a phase 3, double-blind, randomised, placebo-controlled trial. Lancet Oncol 2015;16(4):447456. doi: 10.1016/S1470-2045(15)70056-2.

102. Ismail IH, Davidson R, Gagné JP, Xu ZZ, Poirier GG, Hendzel MJ. Germline mutations in bap1 impair its function in DNA double-strand break repair. Cancer Res 2014;74(16):4282-4294. doi: 10.1158/00085472.CAN-13-3109.

103. Fukuda T, Tsuruga $T$, Kuroda $T$, Nishikawa $H$, Ohta T. Functional link between BRCA1 and BAP1 through histone $\mathrm{H} 2 \mathrm{~A}$, heterochromatin and DNA damage response. Curr Cancer Drug Targets 2016;16(2):101109. doi: 10.2174/1568009615666151030102427.

104. Yu H, Pak H, Hammond-Martel I, et al. Tumor suppressor and deubiquitinase BAP1 promotes DNA double-strand break repair. Proc Natl Acad Sci U S A 2014;111(1):285-290. doi: 10.1073/ pnas.1309085110.

105. Parrotta R, Okonska A, Ronner M, et al. A Novel BRCA1-Associated protein-1 isoform affects response of mesothelioma cells to drugs impairing BRCA1-mediated DNA repair. J Thorac Oncol 2017;12(8):1309-1319. doi: 10.1016/j.jtho.2017.03.023.

106. Borchert S, Wessolly M, Schmeller J, et al. Gene expression profiling of homologous recombination repair pathway indicates susceptibility for olaparib treatment in malignant pleural mesothelioma in vitro. BMC Cancer 2019;19(1):108. doi: 10.1186/s12885-019-5314-0.

107. Thapa B, Salcedo A, Lin X, et al. The immune microenvironment, genome-wide copy number aberrations, and survival in mesothelioma. J Thorac Oncol 2017;12(5):850-859. doi: 10.1016/j.jtho.2017.02.013.

Conflicto de intereses: Los autores declaran no tener conflicto de intereses. 